\title{
STRUCTURE OF SPECTRA OF TIME-DEPENDENT PIEZOPHOTOCONDUCTIVITY
}

\author{
Y. Stakhira, R. Stakhira \\ Ivan Franko National University of Lviv, \\ 50 Drahomanov St., 79005, Lviv, Ukraine \\ e-mail: stakhira@electronics.wups.lviv.ua
}

(Received October 13, 2006; received in final form May 21, 2007)

\begin{abstract}
Some results of a study of the time-dependent piezophotoconductivity (PPC) spectra which are a component of conductivity proportional to the product of light intensity and mechanical pressure of low frequency in the $\mathrm{In}_{4} \mathrm{Se}_{3}$ crystals of the layer structure are shown. Monoaxial pressure of low frequency was created across the layer plane. Spectra of PPC correspond to the range of proper absorption and have an oscillation character. The phase of PPC can be shifted relatively to the pressure phase on $\pi / 2$ and the value of a shift depends on the energy of the light quant. The spectra of orthogonal constituents of time-dependent PPC are in the relation of a function and a derivative of the light quantum energy.

A model of PPC spectra formation on the basis of the analysis of the mutual influence of light and pressure on the interband transitions is proposed. A time-dependent constituent of combined density of states is analyzed. A model of the formation of an oscillatory spectrum on the basis of the U-process mechanism is proposed.
\end{abstract}

Key words: piezophotoconductivity, spectra, U-klapp process

PACS number(s): 72.20.Fr, 72.40.+w

\section{INTRODUCTION}

Piezophotoconductivity (PPC) as a constituent of electroconductivity appears as a result of the mutual light and mechanical pressure action. Their mutual influence on the electron system of a semiconductor appears as the electroconductivity constituent proportional to the product of light and mechanical pressure. We consider that mechanical pressure, $p$, and light intensity, $I$, vary according to the harmonic law. In the case of mutual $p$ and $I$ action the value of PPC, using the method of phase detection, can be easily separated from the other constituents of electroconductivity, which will be written in the general form

$$
\sigma(p, I)=\sigma_{0}+\pi p+\beta I+\gamma I p .
$$

Below we will discuss only the constituent of electroconductivity of semiconductor which is caused by a weak field of mechanical pressure (frequencies are very low) and monochromatic light of constant intensity with the frequencies which correspond to the direct interband transitions.

Experimental studies of PPC in the region of mechanical pressure of audio frequency are extremely limited. Besides such investigations are of great interest and they can be used as the foundation for experimental studies of the fine structure of electron energy spectrum. This follows from the relation between affinity of PPC and piezomodulation spectroscopy [1]. It should be noted that PPC as a kinetic effect covers a much wider set of the processes concerned with the generation and recombination of nonequillibrium charge carriers and their transport in the conditions of time-dependent band energy structure.
In the time-dependent conditions generation time of nonequillibrium carriers by light of constant intensity changes with the frequency of mechanical pressure. It occurs due to the modulation of density of states by mechanical pressure. In these conditions mutual mechanical and light excitations act as a forced factor corresponding to the concentration of charge carriers. That is why we can assume that the concentration type of mechanism dominates in the PPC spectra formation [2].

The goal of this paper is to clarify

- the mechanism of the formation of PPC spectra including their dynamics and conditions of excitation in the quasistationary regime;

- the influence of the law of band dispersion on PPC spectra.

Concerning these goals we will show the main experimental results of PPC spectra of $\mathrm{In}_{4} \mathrm{Se}_{3}$ crystals which turn out to be most typical among others. These results constitute the basis for the proposed model of the formation of the above-mentioned spectra.

\section{THE PROPERTIES OF PPC SPECTRA $\mathrm{OF} \mathrm{In}_{4} \mathrm{Se}_{3}$ CRYSTALS}

Semiconductor crystals $\mathrm{In}_{4} \mathrm{Se}_{3}$ belong to the rhombic syngony with a distinct layer structure. The width of the band-gap is $0.62 \mathrm{eV}$. The crystals possess (i) electron type of conductivity at room temperatures; (ii) intrinsic conductivity; (iii)high sensitivity of photoconductivity [3]; (iv) separate components of tensor of piezoresistance reaching the value of $10^{-6} \mathrm{~m}^{2} / \mathrm{N}[4]$. 


\section{Y. STAKHIRA, R. STAKHIRA}

Experimental studies of PPC were carried out on the equipment which included the source of monochromatic light, the block for the creation of varying mechanical pressure in the sample and the block of the registration of PPC current. This makes it possible to detect the phase of the measured signal. Investigations were carried out at constant light illumination and low frequency monoaxial pressure.

The technique of studying the PPC spectra is presented in [2]. Measurements were carried out on the samples which were a naturally cleaved or parallel-sided plate, the larger plane of which was normal to the cleaved one. They were placed between two parallel-sided quartz plates in a way permitting, depending on the geometry of the experiment, to illuminate a free larger surface of the sample. In the other case one of the quartz plates served as a window for the light. The condition of the sample surface and its mechanical contact with quartz plates have been under precise control in order to avoid interference phenomena. The varied mechanical pressure was created in the previously clamped sample by an electromagnetic transformer. The value of this pressure was not higher than $5 \cdot 10^{4} \mathrm{~N} / \mathrm{m}^{2}$, and the amplitude of the varying component was its tenth part. The range of frequency was $20-2000 \mathrm{~Hz}$. The decay time of natural vibrations of the clamped sample was estimated according to time decay of the current pulse caused by pulse pressure. The value of this time was not more than $10^{-5}$ sec.

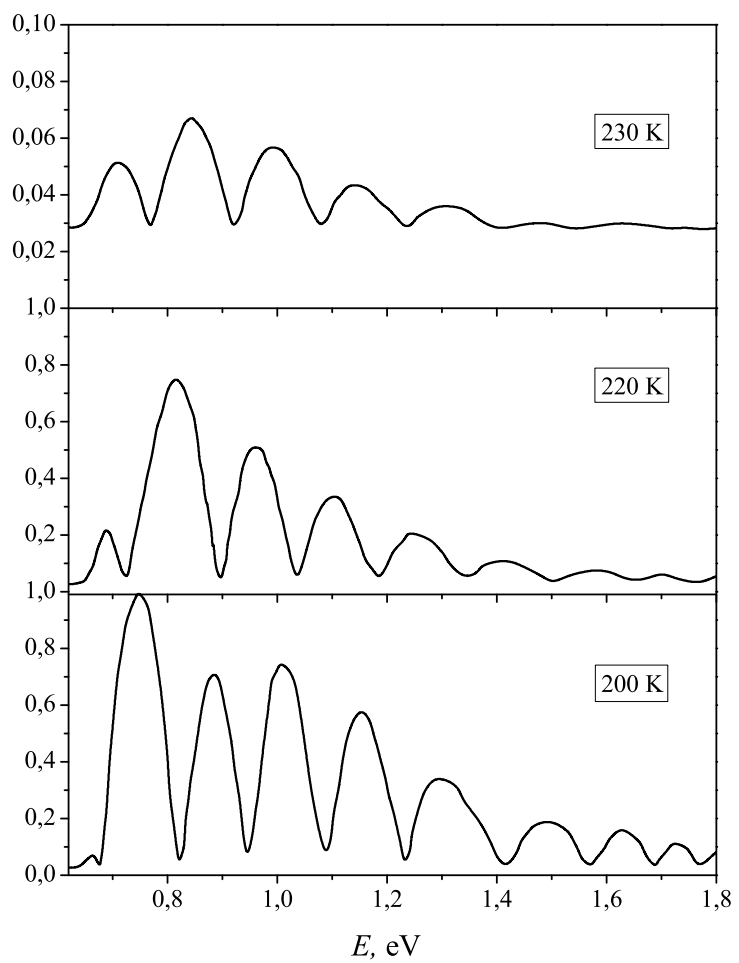

Fig. 1. Spectra of the PPC amplitude measured at different temperatures.

The spectrum of PPC can be considered as a system of bands the spectral position of which corresponds to the fundamental absorption where the bands are as a cer- tain spectral interval with a sharp increase or decrease of the PPC regions. In separate PPC bands at the same conditions the excitation can exceed the value of piezoconductivity by 1-2 orders and it can be of the same value as photoconductivity.

The spectra of the PPC amplitude of the $n$-type sample of $0.2 \mathrm{~mm}$ thickness measured at different temperatures are shown in Fig. 1. The position and value of maximums of PPC spectra depend on the conditions of excitation and partly it can be corrected by the pressure amplitude.

The instability in the band maximums (the maximum corresponds to the PPC increase) was observed in some cases. Such instabilities appear in a set of fine spectral lines of particularly high amplitude, see Fig. 2. Spectral band width can vary significantly for different cases and experimental conditions, but the general view of spectral dependence remains the same.

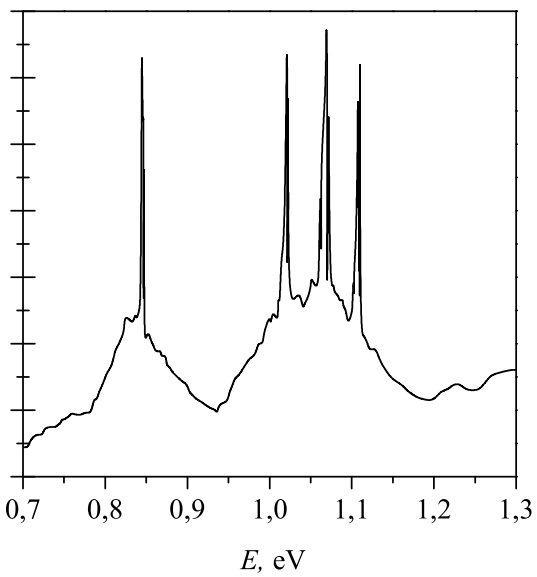

Fig. 2. Fine spectral lines structure of PPC spectra.

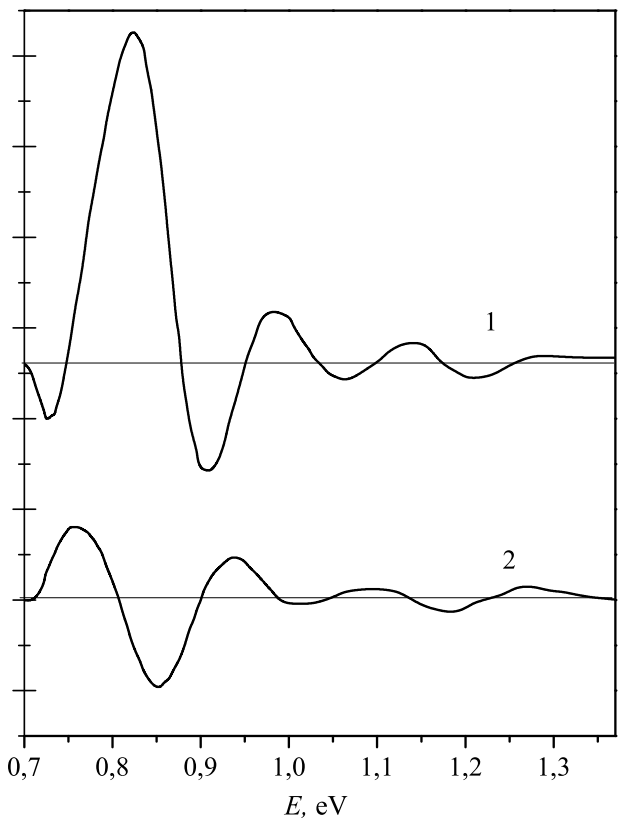

Fig. 3. Spectral dependences of orthogonal components of PPC: $1-$ inphase with pressure, $2-\pi / 2$ phase shifted. 
The peculiarity of the dynamics of PPC spectra is phase displacement of $\mathrm{PPC}$ in respect to the phase of a modulated mechanical pressure on the angle value $\varphi$, which depends on the energy of light quantum (it can reach the value $\pi / 2$ ). Shown in Fig. 3 are spectral dependences of orthogonal components of the PPC: inphase with pressure and $\pi / 2$ phase shifted with respect to the pressure phase.

The spectra of PPC orthogonal constituents do not vary in band set and their spectral width, while spectral position of the bands is different. As one can see in Fig. 3 the spectra of orthogonal constituents are in relationship as function and derivative on energy of light quantum. It should be noted that the existence of phase shifted PPC constituent excludes any significant influence of unsupervised interference phenomena on these spectra formation. This conclusion was confirmed by experiments in which the pressure in the sample was created in the direction normal to the illuminated free plane.

By summing up the above-given results and considering their reproduction in $\mathrm{In}_{4} \mathrm{Se}_{3}$ crystals [2], two typical peculiarities of time-dependent PPC should be marked:

- oscillative character

- spectral dependence of phase shift.

Let us consider one of the possible models in order to explain physical grounds for these peculiarities.

\section{DYNAMICS OF ABSORPTION FACTOR AT QUASISTATIONARY CONDITIONS}

Let us estimate a dependence of the absorption factor on time considering conditions which follow from the quasistationary regime. Letus restrict ourselves to insignificant pressures. Such pressures lead to crystal deformation which practically does not change sizes and shape of Brillouin zone, while changes in energy structure are caused by the energy redistribution over electron states in bands [5]. That is the reason for the energy width $\mathcal{E}=E_{c}(\mathbf{k})-E_{v}(\mathbf{k})$ between bands for the given wave vector $\mathbf{k}$ to depend on pressure and thus become a time-dependent function. It is the main reason for the time-dependent combined density of states and it has a direct relatedness to the dynamics of the absorption factor.

In the case of transitions from a completely occupied valence band to a completely empty conduction band the number $d z$ of absorbed photons per time unit from the light flow of single intensity within the plane of single thickness, which forms a spectral dependence and the value of absorption factor is as follows

$$
d z=\frac{4 \pi}{\hbar} \frac{d}{d t} \int_{E_{c}-E_{v}=\mathcal{E}}\left|P_{c v}\right|^{2} \delta_{s}(\mathcal{E}-\hbar \omega) \operatorname{tg}(\mathcal{E}, t) \mathrm{d} \mathcal{E}
$$

here $g(\mathcal{E}, t)$ is combined density of states, $\left|P_{c v}\right|^{2}$ is the square of matrix element. In respect to this the absorption factor consists of two components: the first one is proportional to combined density of states, and the second is proportional to the speed of its change. Assuming that $g(\mathcal{E}, t) \sim \sin (\Omega t)$ and using average value of the probability of transition during a period we will represent absorption factor as follows

$$
\alpha=\alpha_{0}+\alpha_{p} \sin (\Omega t+\varphi),
$$

where $\alpha_{0}$ is the time independent component $\alpha_{p}^{2}=$ $\alpha_{s}^{2}+\alpha_{a}^{2}$ and $\tan \varphi=\frac{\alpha_{a}}{\alpha_{s}} ; \alpha_{s}$ and $\alpha_{a}$ are amplitude of inphase and phase shifted on $\pi / 2$ components.

As a consequence of such energy redistribution in bands the energy of conduction and valence bands $E_{c}(\mathbf{k}), E_{v}(\mathbf{k})$, respectively take an additional value $\Delta E_{c}(\mathbf{k}), \Delta E_{v}(\mathbf{k})$. It happens due to the deformation process. In the energy structure of undistorted crystal the $E_{c}(\mathbf{k})+\Delta E_{c}(\mathbf{k}), E_{v}(\mathbf{k})+\Delta E_{v}(\mathbf{k})$ energies correspond to that in the states $\mathbf{k}_{c}+\Delta \mathbf{k}_{c}, \mathbf{k}_{v}+\Delta \mathbf{k}_{v}$ of conduction and valence bands, respectively

Thus the energy distance $\mathcal{E}$ which in the state $\mathbf{k}$ of unpressed crystal is equal to

$$
\mathcal{E}=E_{c}(\mathbf{k})-E_{v}(\mathbf{k})
$$

during deformation takes an addition value $\Delta E(\mathbf{k})=$ $\Delta E_{c}(\mathbf{k})-\Delta E_{v}(\mathbf{k})$.

The specified value of interband distance $\mathcal{E}$, which corresponds to the direct transition, is realized during the crystal deformation as a difference between energy of the state of conduction band, $\mathbf{k}+\Delta \mathbf{k}$, and valence band, $\mathbf{k}+\Delta \mathbf{k}$, as follows

$$
E_{c}(\mathbf{k}+\Delta \mathbf{k})-E_{v}(\mathbf{k}+\Delta \mathbf{k})=\mathcal{E}
$$

where $\Delta \mathbf{k}$ equals

$$
\Delta \mathbf{k}=\frac{\nabla_{k} E_{c}(\mathbf{k}) \mathbf{k}_{c}-\nabla_{k} E_{v}(\mathbf{k}) \mathbf{k}_{v}}{\nabla_{k} E_{c}(\mathbf{k})-\nabla_{k} E_{v}^{p}(\mathbf{k})} .
$$

It should be noted that in the general case the $\Delta \mathbf{k}$ dependence on the wave vector can be complicated and it will not be described by Eq. (6). This can happen in a semiconductor with a multi-valley zone structure with nonequivalent valleys. That is why let us represent $\Delta \mathbf{k}$ as follows

$$
\Delta \mathbf{k}=\varkappa(\mathbf{k}) \mathbf{k} p
$$

In the energy structure of the initial crystal interband energy the distance corresponds to each wave vector taken from the interval $\mathbf{k}+\varkappa(\mathbf{k}) \mathbf{k} p$. The increment of energy due to crystal deformation in a sum with the initial energy distance gives $\mathcal{E}$. Thus the influence of mechanical pressure on the interband energy structure of the semiconductor comes to the shift of interband energy distance $\mathcal{E}$ from the state $\mathbf{k}$ to the state $\mathbf{k}+\varkappa(\mathbf{k}) \mathbf{k} p$.

The electron density of states was calculated by means of the usual method in which Eq. (5) plays the role of the $\delta$-function argument. The root of the equation was estimated by the successive approximations method. The root of Eq. (4) was accepted as zero approximation which 
was shown as a module of the corresponding wave vector $k_{0}=\eta(\mathcal{E})$. The roots of Eq. (4) should satisfy the following equation

$$
k+\varkappa(k) k p=\eta(\mathcal{E}),
$$

where $\varkappa(k)$ belongs to the interval of wave vector values in the vicinity of the given wave vector $k_{0}$ in which the band gap energy remains constant during the deformation process.

The roots of Eq. (8) in the first approximation preserving the constituent linear dependence on pressure are as follows

$$
k_{1}=k_{0}\left(1-\varkappa\left(k_{0}\right) p\right)
$$

where $k_{0}=\eta(\mathcal{E})$. In such a way the time dependent electron density of states is a function of argument $k_{1}=k_{0}\left(1-\varkappa\left(k_{0}\right) p\right)$. It can be defined considering a certain structure and the consequences of mechanical pressure affect it.

In the general case it is of the form

$$
g(\mathcal{E}, t)=g(\eta(\mathcal{E})[1-\varkappa(\eta(\mathcal{E}) p)])
$$

and the time derivative reads

$$
\frac{d g(\mathcal{E}, t)}{d t}=-\frac{d g\left(k_{1}\right)}{d k_{1}} \eta(\mathcal{E}) \varkappa(\eta(\mathcal{E})) \frac{d p}{d t} .
$$

The absorption factor for this problem is as follows

$$
\alpha(\hbar \omega)=\alpha_{0}(\hbar \omega)+\alpha_{s}(\hbar \omega) \sin (\Omega t)+\alpha_{a}(\hbar \omega) \cos (\Omega t),
$$

in which $\alpha_{s}$ and $\alpha_{a}$ are determined by the corresponding terms in expressions (10) and (11). The spectra of these terms relate the each other by the expression which follows from (10) and (11). It should be mentioned that the main role in the spectrum formation of the timedependent part of absorption factor and PPC spectra is of importance for the value $\varkappa(\mathbf{k}) \mathbf{k} p$, respectively.

\section{SPECTRUM OF TIME-DEPENDENT PART OF ABSORPTION FACTOR}

All the above-mentioned reasons and general properties of the structure of electron energy spectrum allow to conclude that in the general case the oscillatory character of PPC spectra cannot be caused exclusively by the band energy structure. It is unlikely for the dominant role of a concrete energy structure to be the main reason for the oscillatory character of PPC nonstationary spectra.

In this paper we propose the mechanism of nonstationary PPC spectra formation which consists of the modulation of the energy dependence of combined density of states by a mechanical pressure. The direct modulator factor is the $U$-process of electron dissipation caused by mechanical pressure. Concerning the bands it should be mentioned that pressure as a dissipative reason led to a shift of the wave vector $\mathbf{k}$ to the state $\mathbf{k}+\varkappa(\mathbf{k}) \mathbf{k} p$ causing different consequences. Particularly, because of varied band occupation such a dissipation is effective mainly concerning the electrons of the valence band participating in the $U$-processes. As a result of the $U$-processes the velocity of some electrons is inverse. As a consequence of this occurs a sharp increase of combined density of states in the vicinity of the corresponding wave vectors.

The wave vectors $\mathbf{k}_{n}$, to which such processes are respected, satisfy the equality

$$
\mathbf{k}+\frac{1}{2} \varkappa(\mathbf{k}) \mathbf{k} p=\frac{\pi}{2 d^{2}} \mathbf{d}
$$

in which $d$ is the period of the crystal lattice.

The $U$-process realization, occurring for the electron states in respect to Eqs. (8) and (13) is joined by a sharp increase of combined density for the corresponding energy values that are caused by a decrease of the difference $\left|\nabla_{k} E_{c}(\mathbf{k})-\nabla_{k} E_{v}(\mathbf{k})\right|$ for these states. That is why the $U$-processes cause the peculiarities of the spectral structure of the nonstationary proper absorption factor similar to the Van Hove ones in the absorption spectra of unpressed crystals [6]. In contrast to the last ones the spectral position of the extremes of the nonstationary absorption factor depends not only on a concrete energy structure but also on the value $\Delta \mathbf{k}=\varkappa(\mathbf{k}) \mathbf{k} p$ which yields the forced factor.

Finally, let us consider how the proposed model corresponds to the obtained experimental results. For this purpose let us consider that the main mechanisms of forming PPC time-dependent spectra are mainly caused by the dynamics of nonequilibrium concentration of charge carriers including their generation and recombination in the conditions of action of the time-dependent mechanical pressure. In the simplest case the equation for the concentration of charge carriers $n$ is of the form [2]

$$
\frac{d^{2} n}{d t^{2}}+\frac{1}{\tau} \frac{d n}{d t}+\Omega_{0}^{2} n=G \sin (\Omega t+\varphi)
$$

here $\tau$ is the total relaxation time which includes relaxation time of mechanical pressure and concentration of nonequilibrium charge carriers, $\Omega_{0}$ is the frequency of self-oscillations of the sample and $G \sin (\Omega t+\varphi)$ is the total generation rate.

The total generation rate $G \sin (\Omega t+\varphi)$, which plays in Eq. (14) the role of a forced factor, is a sum of the speed of the optical generation $G_{s} \sin (\Omega t+\varphi)$ and generation rate $G_{p} \sin (\Omega t)$ caused by the pressure $p=p_{s}+$ $p_{0} \sin (\Omega t)$. Besides, we assume that for light of constant intensity the time-dependent optical generation regime is due to time-dependent absorption factor $\alpha$. Among all the terms which form the forced factor in Eq. (14) only the absorption factor is determining as regards PPC spectra.

For this purpose we shall represent the simplest solution of Eq. (14) on the right hand-gide of whose constituents the generation rate Eq. (12) $\alpha_{s}(\hbar \omega)$ and $\alpha_{a}(\hbar \omega)$ is included. At steady regime this solution is of the form of

$$
n(t)=n_{0}+n_{p}(\hbar \omega) \sin (\Omega t+\varphi),
$$


where $n_{0}$ is the equillibrium concentration, $n_{p}=$ $\sqrt{n_{s}^{2}+n_{a}^{2}}, n_{s}$ and $n_{a}$ corresponds to the constituents of the nonequillibrium concentration of charge carriers which are linear to $\alpha_{s}, \alpha_{a}$, respectively.

First of all let us note that the values $n_{s}$ and $n_{a}$ and their spectra are a consequence of the corresponding energy dependence of time-dependent components of combined electron density of the states $g_{s}(\mathcal{E})$ and $g_{a}(\mathcal{E})$, Eqs. (10) and (11). The shift of $n_{s}$ and $n_{a}$ spectra caused by these components leads to the PPC phase shift in respect to the pressure phase on the value of the angle $\varphi=\arctan \frac{n_{a}}{n_{n}}$ and its spectral dependence.

The results of experimental studies of the PPC spectra structure for several semiconductors $\left(\mathrm{In}_{4} \mathrm{Se}_{3}\right.$, GaSe, $\mathrm{Tl}_{2} \mathrm{~S}$ ) agree qualitatively with the conclusions which follow from our model. It concerns particularly the shape and sizes of spectral bands, the dependence of the number of bands on the conditions of perturbation within the region corresponding to the interband absorption. Hereby the observed spectral instability in the bands maxima is revealed. This confirms that the observed experimental bands in PPC spectra are the results of averaging the corresponding effects over the crystal volume.

Summing up all the aforesaid we can conclude that the mutual action of light and varying pressure causes the appearance of discrete resonance centers which while absorbing light promote a sharp increase of concentration of the nonequillibrium of charge carriers for the corresponding light quantum energies. The energy position of these centers within the energy structure of a semiconductor can be experimentally found by the methods of modulation spectroscopy.
[1] M. Cardona, Modulation spectroscopy (New York-London, 1969).

[2] J. M. Stakhira, R. J. Stakhira, V. P. Savchyn. Ukr. Phys. J. 50, 587 (2005).

[3] I. P. Zhad'ko, E. I. Razhba, V. A. Romanov, J. M. Stakhira, K. D. Tovstyuk, Fiz. Tverd. Tela 7, 1777 (1965).
[4] V. P. Savchyn, J. M. Stakhira, Fiz. Tekhn. Polupr. 12, 2137 (1978).

[5] G. L. Bir, G. E. Pikus, Symmetry and Strain-Induced Effect in Semiconductor (Wiley, New York, 1974).

[6] L. van Hove Phys. Rev. 89, 1189 (1953).

\title{
СТРУКТУРА СПЕКТРІВ НЕСТАЦІОНАРНОЇ П'ЄЗОФОТОПРОВІДНОСТИ
}

\author{
Й. Стахіра, Р. Стахіра \\ Лъвівсъкий начіоналъний університет імені Івана Франка \\ вул. Драгоманова, 50, Лъвів, 79005, Украӥна
}

\begin{abstract}
Наведено результати вивчення спектрів нестаціонарної п'єзофотопровідности (ПФП) - складника провідности напівпровідника, який пропорційний добуткові інтенсивности світла й величини механічного тиску низької частоти. Експериментальні дослідження проведено на кристалах шаруватої структури $\operatorname{In}_{4} \mathrm{Se}_{3}$. Одновісний тиск низької частоти створювали нормально до площини шарів. Спектри ПФП відповідають діяпазонові власного поглинання й мають осциляційний характер. Фаза ПФП зміщена стосовно фази тиску на величину кута до $\pi / 2$ і залежить від енергї̈ кванта світла. Спектри ортогональних складників нестаціонарної ПФП перебувають у співвідношенні як функція й похідна по енергїі кванта світла.

Запропоновано модель формування спектрів ПФП на основі аналізу спільного впливу світла й тиску на міжзонні переходи. Проаналізовано нестаціонарний складник комбінованої густини станів. Запропоновано модель формування осциляційного характеру спектра на основі механізмів перекидання.
\end{abstract}

